\title{
Analysis of benign ventricular tumors: Long-term outcome after resection
}

\author{
Andrew W. EIBardissi, BS, ${ }^{a}$ Joseph A. Dearani, MD, ${ }^{b}$ Richard C. Daly, MD, ${ }^{\mathrm{b}}$ Charles J. Mullany, MD, ${ }^{\mathrm{b}}$ \\ Thomas A. Orszulak, MD, ${ }^{\mathrm{b}}$ Francisco J. Puga, MD, ${ }^{\mathrm{b}}$ and Hartzell V. Schaff, MD ${ }^{\mathrm{b}}$
}

From the Harvard School of Public Health, ${ }^{\mathrm{a}}$ Boston, Mass; and Division of Cardiovascular Surgery, Mayo Clinic and Foundation, ${ }^{\mathrm{b}}$ Rochester, Minn.

Received for publication Aug 28, 2007; revisions received Oct 11, 2007; accepted for publication Oct 19, 2007.

Address for reprints: Andrew W. ElBardissi, BS, Harvard School of Public Health 677 Huntington Ave, Boston, MA 02115 (E-mail: delbardissi@partners.org).

J Thorac Cardiovasc Surg 2008;135:1061-8 $0022-5223 / \$ 34.00$

Copyright $\odot 2008$ by The American Association for Thoracic Surgery

doi:10.1016/j.jtcvs.2007.10.048
Objective: We sought to compare clinical and pathologic characteristics of ventricular tumors and to detect whether differences exist in short- and long-term survival after resection.

Methods: From 1964 to 2005, 323 patients had cardiac surgery for resection of primary cardiac tumors; 53 (16\%) patients had primary ventricular tumors. We randomly sampled 53 characteristics of ventricular tumors.

Results: Patients with ventricular tumors were younger than those with atrial tumors (34.8 vs 54.6 years; $P<.0001$ ). New York Heart Association functional status was similar at presentation, although patients with atrial tumors had increased risk of atrial fibrillation $(P<.05)$, thromboembolic events $(P=.04)$, and mitral stenosis $(P=$ $.008)$ at the time of presentation. Patients with ventricular tumors had an increased incidence of myocardial invasion $(14 \%$ vs $2 \% ; P=.02)$ and had significantly longer cardiopulmonary bypass ( 80 vs 65 minutes; $P<.05$ ) and crossclamp (52 vs 39 minutes; $P=.03$ ) times. Operative mortality was $4 \%$ and $0 \%$ in the ventricular and atrial groups, respectively $(P=$ not significant). Follow-up was obtained in $89 \%$ of patients at a mean follow-up time of 7.21 years. A Kaplan-Meier survival plot demonstrated no difference in survival characteristics of both groups. At follow-up, $81 \%$ and $74 \%$ of ventricular and atrial tumors, respectively, were minimally symptomatic (New York Heart Association class I/II; $P=.13)$. Patients with atrial and ventricular tumors had a $6 \%$ and $0 \%$ tumor recurrence rate, respectively $(P=.12)$.

Conclusion: Surgical resection for ventricular tumors is effective and results in excellent long-term outcome. Early surgical treatment should be strongly considered in patients with primary ventricular tumors.

$\mathrm{P}$ rimary cardiac tumors are rare and occur with a lifetime incidence of $0.0017 \%$ to $0.02 \%{ }^{1-3}$ Previous literature has suggested that $75 \%$ of all primary cardiac tumors are benign, with $75 \%$ of these being myxomas that occur in the left atrium. ${ }^{4-6}$ Despite the rarity of cardiac tumors, much is known about the clinical presentation and the early and late condition of patients who undergo surgery for curative resection. Many of these results, however, are based on tumors confined to the atria or those occurring in the pediatric (most often infant) population. There have been few reports of primary cardiac tumors that originate from the ventricles in the adult population; thus, there is a paucity of knowledge regarding pathologic characteristics, clinical presentation, anatomic and hemodynamic profile, and early and late outcome of patients who undergo resection. Furthermore, while the consensus is that patients with benign atrial tumors should be offered curative resection at the time of presentation, there have been no studies determining whether a similar therapeutic algorithm should be pursued in patients with ventricular tumors.

The purpose of this study was to evaluate the epidemiology, presentation, and pathophysiologic characteristics of patients with ventricular tumors. Additionally, we sought to evaluate the effectiveness and long-term outcome after curative resection of primary ventricular tumors. To accomplish these goals, we designed a retrospective cohort study 
consisting of all patients who were treated surgically for primary ventricular tumors at our institution. Furthermore, to provide a context in which to interpret the unique risks (both hemodynamic and anatomic) and effectiveness of surgical resection in patients with ventricular tumors, we enrolled a reference group consisting of randomly chosen patients who had primary atrial tumor resection at our institution during the same time interval.

\section{Patients and Methods}

From July 7, 1964, to April 19, 2005, 323 patients had cardiac surgery for resection of primary cardiac tumors. Inclusion criteria into the study group included patients who presented to our institution, were given the diagnosis of a ventricular tumor, and were subsequently treated surgically with clinical and histologic confirmation of a ventricular tumor originating from the heart. Exclusion criteria included patients with a cardiac tumor of secondary origin (metastasis to the heart) or those who presented to our institution with a ventricular tumor and were not offered surgical resection; these included patients with significant tumor invasiveness, infants with ventricular tumors and minimal hemodynamic effects, and patients with metastatic cancer to the heart. Fifty-three (16\%) patients with primary ventricular tumors fit these criteria and make up the study group used for this analysis. Of the remaining 270 primary cardiac tumors, we chose to enroll a control group consisting of 1:1 ratio of study group to control group patients who had primary atrial tumor resection during the same time interval at our institution. Thus, 53 patients with primary atrial tumors were randomly chosen from the study base to serve as the reference group, thereby providing a context in which to evaluate the unique clinical characteristics and surgical outcome of patients who underwent ventricular tumor resection. A retrospective cohort study was performed, and medical records were reviewed for patient demographics, cardiac medical and surgical history, operative procedure, preoperative and postoperative data, early and late morbidity, and survival.

\section{Statistical Analysis}

Demographic and other patient-related data were obtained from Mayo Clinic Rochester medical records. Follow-up information was obtained from subsequent clinic visits, written correspondence from local physicians, and mailed questionnaires to patients or families. Continuous variables are expressed as a mean \pm standard deviation. The Student $t$ tests and Pearson $\chi^{2}$ tests were used to analyze continuous and categorical variables, respectively. Multivariate linear regression and logistic regression analyses were used to determine associations between continuous and categorical outcomes, respectively. A Kaplan-Meier survival curve was constructed to assess long-term outcome and a log-rank test was used to determine significant differences in survival characteristics between the study and control groups. Additionally, a Cox proportional hazards model was used to assess factors affecting long-term survival. Early operative mortality was defined as death occurring within 30 days of operation or at any time during the index hospitalization. The Mayo Foundation Institutional Review Board approved this study, and all patients or their families gave written informed consent.

\section{Results}

Demographic and patient presentation characteristics are shown in Table 1. Patients with ventricular tumors were significantly younger than those with atrial tumors (34.8 vs 56; $P<.0001)$. Furthermore, 3 distinct ventricular tumor types contributed to a multivariate regression model $\left(R^{2}=\right.$ $0.33, P<.001)$ predicting time of presentation; these included fibromas (mean, 22.5 years; $P<.03$ ), hamartomas (mean, 12.5 years; $P=.03$ ), and papillary fibroelastomas (mean, 57.5 years; $P<.02$ ). Medical risk factors were similar between both groups, although patients with atrial tumors had a higher incidence of previous cardiac surgery $(P=$ .0019). Functional status at the time of presentation was also similar between groups, although patients with atrial tumors more commonly presented with dyspnea (47\% vs $28 \%$; $P=.045)$ as the primary symptom and had increased risk of presenting in atrial fibrillation $(17 \%$ vs $4 \% ; P=.05)$ and prior thromboembolic events $(19 \%$ vs $6 \% ; P=.04)$. Patients with ventricular tumors had increased risk of documented ventricular arrhythmias (21\% vs $4 \% ; P=.008)$. Histologic diagnosis was confirmed on the basis of microscopic tissue analysis after resection of the tumor. The overall distribution of histologic variants differed significantly between atrial and ventricular tumors (Table 2$)$; fibromas $(P<.0001)$ and hamartomas $(P=.042)$ occurred exclusively in the ventricles and myxomas were $7(3.25,15.1 ; P<.001)$ times more likely to occur in the atria than the ventricles.

\section{Preoperative Diagnosis}

The majority of diagnoses were made by echocardiography in both groups, although cardiac magnetic resonance imaging was used more often in diagnosing ventricular tumors $(P=$ $0.011)$. Atrial tumors most often occurred in the left atrium $(81 \%)$ and frequently originated from the atrial septum $(60 \%)$. A similar distribution was appreciated with ventricular tumors, with $75 \%$ originating from the left ventricle and $33 \%$ of these arising from the ventricular septum. Among ventricular tumors, left-sided predominance was constant among different histologic types, with the exception of hamartomas, which occurred most often in the right ventricle (75\%; $P=.03)$. Seven (15\%) ventricular septal tumors extended into the outflow tract and caused a partial outflow tract obstruction.

Ejection fraction was similar between both groups (Table 1), but mitral stenosis (owing to tumor obstruction) was more likely to occur in cases of atrial tumors $(P=.007)$. Mitral regurgitation was more likely to occur with ventricular tumors $(P<.07)$, although size and/or specific tumor type were not associated with the occurrence of mitral regurgitation. Subgroup analysis revealed that among ventricular tumors, myxomas were highly associated with tricuspid regurgitation $(P=.046)$ and patients with ventricular papillary fibroelastomas were more likely to have aortic regurgitation $(P=.047)$. 
TABLE 1. Preoperative patient demographics, symptomatology, and diagnostic information

\begin{tabular}{|c|c|c|c|c|c|}
\hline \multicolumn{3}{|c|}{ Primary ventricular tumors } & \multicolumn{2}{|c|}{ Primary atrial tumors } & \multirow[b]{2}{*}{$P$ value } \\
\hline & & $95 \% \mathrm{Cl}$ & & $95 \% \mathrm{CI}$ & \\
\hline Age & 34.8 & 28,42 & 56 & 52,61 & $<.0001$ \\
\hline Male & $27(51 \%)$ & & $20(38 \%)$ & & .17 \\
\hline \multicolumn{6}{|l|}{ Medical/surgical history } \\
\hline Family history of cardiac tumor & $1(2 \%)$ & & $2(4 \%)$ & & .56 \\
\hline Hypertension & $13(25 \%)$ & & $13(25 \%)$ & & 0.999 \\
\hline Diabetes mellitus & $2(4 \%)$ & & $5(9 \%)$ & & .15 \\
\hline Previous cardiac surgery & $6(11 \%)$ & & $8(15 \%)$ & & .57 \\
\hline CAD & $3(6 \%)$ & & $15(28 \%)$ & & .0019 \\
\hline HOCM & $4(8 \%)$ & & 0 & & .08 \\
\hline \multicolumn{6}{|l|}{ NYHA status } \\
\hline Class I & $24(48 \%)$ & & $16(31 \%)$ & & .11 \\
\hline Class II & $11(22 \%)$ & & $16(31 \%)$ & & \\
\hline Class III & $13(26 \%)$ & & $20(38 \%)$ & & \\
\hline Class IV & $2(4 \%)$ & & 0 & & \\
\hline \multicolumn{6}{|l|}{ Presentation } \\
\hline Angina & $11(21 \%)$ & & $10(19 \%)$ & & .8 \\
\hline Dyspnea & $15(28 \%)$ & & $25(47 \%)$ & & .0451 \\
\hline Palpitations & $12(23 \%)$ & & $8(15 \%)$ & & .32 \\
\hline Syncope & $10(9 \%)$ & & $4(8 \%)$ & & .09 \\
\hline TIA & $3(6 \%)$ & & $6(11 \%)$ & & .3 \\
\hline Constitutional symptoms & $7(13 \%)$ & & $14(26 \%)$ & & .09 \\
\hline Atrial fibrillation & $2(4 \%)$ & & $9(17 \%)$ & & .026 \\
\hline Ventricular tachycardia & $11(21 \%)$ & & $2(4 \%)$ & & .008 \\
\hline Thromboembolism & $3(6 \%)$ & & $10(19 \%)$ & & .04 \\
\hline \multicolumn{6}{|l|}{ Diagnosis } \\
\hline Echocardiography & $41(77 \%)$ & & $46(88 \%)$ & & \\
\hline $\mathrm{EF}$ & $62 \%$ & 59,66 & $61 \%$ & 58,64 & .76 \\
\hline RVSP & 31 & 23,38 & 36 & 28,44 & .17 \\
\hline MR & $9(17 \%)$ & & $3(6 \%)$ & & .07 \\
\hline MS & 0 & & $7(13 \%)$ & & .007 \\
\hline TR & $5(10 \%)$ & & $2(4 \%)$ & & .23 \\
\hline PR & $3(6 \%)$ & & $1(2 \%)$ & & .3 \\
\hline Cardiac MRI & $6(11 \%)$ & & 0 & & .011 \\
\hline Angiography & $8(15 \%)$ & & $6(11 \%)$ & & .6 \\
\hline
\end{tabular}

Boldface indicates statistical significance. $C l$, Confidence interval; $C A D$, coronary artery disease; HOCM, hypertrophic obstructive cardiomyopathy; NYHA, New York Heart Association; TIA, transient ischemic attack; $E F$, ejection fraction; $R V S P$, right ventricular systolic pressure; $M R$, mitral returgitation; $M S$, mitral stenosis; $T R$, tricuspid regurgitation; $P R$, pulmonary regurgitation; $M R I$, magnetic resonance imaging.

Atrial tumor burden (calculated as the volume of excised tumor) was $48 \pm 13.5 \mathrm{~cm}^{3}$ and ventricular tumor burden was $77 \pm 14 \mathrm{~cm}^{3}(P=.14)$. Multivariate stepwise linear regression $\left(R^{2}=0.22 ; P<.01\right)$ indicated that fibromas (mean, $120 \mathrm{~cm}^{3} ; P=.009$ ) and lipomas (mean, $195 \mathrm{~cm}^{3}$; $P=.007)$ were significantly larger than the remainder of the ventricular tumor cohort. A similar regression model for atrial tumors did not reveal differences between histologic types of tumors.

\section{Surgical Resection}

Surgical resection was electively pursued in all patients; Table 3 outlines the operative parameters. Histologic confirmation was obtained by tissue analysis, whereas tumor inva- siveness was determined at the time of surgery by the operating surgeon assessing the anatomic characteristics of the tumor. Patients with ventricular tumors had longer bypass $(P<.05)$ and crossclamp $(P=.03)$ times than patients with atrial tumors. Surgical approach to tumor resection varied significantly between both groups, with the majority of atrial tumors resected with either a single $(n=47,90 \%)$ or biatrial $(\mathrm{n}=4,8 \%)$ approach, whereas a significant proportion of ventricular tumors were resected via ventriculotomy $(\mathrm{n}=$ $19,44 \%)$ or with an extracardiac approach $(\mathrm{n}=11,26 \%)$. Papillary fibroelastomas were more commonly resected through an aortotomy than other ventricular tumors $(\mathrm{n}=5$, $P=.005)$, and fibromas were more likely to be resected with an extracardiac approach $(P<.001)$ or by 
TABLE 2. Distribution of histologic variants

\begin{tabular}{|c|c|c|c|}
\hline & $\begin{array}{c}\text { Primary } \\
\text { ventricular } \\
\text { tumors }\end{array}$ & $\begin{array}{c}\text { Primary } \\
\text { atrial } \\
\text { tumors }\end{array}$ & $P$ value \\
\hline Myxoma & $6(11 \%)$ & $42(79 \%)$ & $<.0001$ \\
\hline Fibroma & $18(34 \%)$ & 0 & $<.0001$ \\
\hline Papillary fibroelastoma & $11(19 \%)$ & $4(8 \%)$ & .05 \\
\hline Rhabdomyoma & $1(2 \%)$ & $1(2 \%)$ & 0.999 \\
\hline Lipoma & $4(8 \%)$ & $3(6 \%)$ & .7 \\
\hline Hamartoma & $4(8 \%)$ & 0 & .042 \\
\hline Hemangioma & $2(4 \%)$ & 0 & .15 \\
\hline Carcinoid & $1(2 \%)$ & 0 & .32 \\
\hline Other benign tumors & $5(10 \%)$ & 0 & .09 \\
\hline Angiosarcoma & $1(2 \%)$ & $1(2 \%)$ & 1 \\
\hline Malignant fibrohistosarcoma & 0 & $1(2 \%)$ & .32 \\
\hline
\end{tabular}

Boldface indicates statistical significance.

ventriculotomy $(P=.01)$ than other ventricular tumors. The approach to surgical resection was dependent solely on the location of tumors; fibromas and lipomas were extracardiac myocardial tumors occasionally requiring an intracardiac approach, whereas papillary fibroelastomas most frequently occurred in the left ventricular outflow tract, so that aortotomy provided the optimal surgical approach for resection. The remaining histologic variants of ventricular tumors were predominantly intracardiac and were approached through a ventriculotomy. Ventricular tumors demonstrated evidence of local invasion more often than their atrial counterparts ( $14 \%$ vs $2 \% ; P=.03)$. A multivariate logistic model including histologic tumor types, maximum tumor diameter, and tumor burden revealed maximum tumor diameter to be an independent predictor of local invasion for ventricular tumors (mean $=7.85 \mathrm{~cm} ; P=.01$ ); a similar model for atrial tumors revealed no significant predictive factors of tumor invasion. Despite the increased frequency of tumor invasion in the ventricular tumor cohort, $82 \%$ were resected with negative margins. Pericardial patches were used for closure of atrial/ ventricular septal defects in 14 (26\%) patients who had atrial tumor resection and $1(2 \%)$ patient who had ventricular tumor resection, respectively.

Concomitant procedures were similar among both groups. There was a trend toward increased coronary artery bypass graft procedures $(P=.06)$ in patients with atrial tumors; however, after controlling for age, this increased frequency was likely due to confounding $(P=.535)$. Operative and 30-day survival was $100 \%$ in the atrial tumor group and 96\% (2 deaths) in the ventricular tumor group; one death occurred in a pediatric patient with a large ventricular fibroma who was unable to be weaned from cardiopulmonary bypass, and the second death occurred in a patient with chronic renal and hepatic insufficiency who underwent hemangioma resection but died shortly after surgery of progressive renal and hepatic failure.
TABLE 3. Surgical characteristics

\begin{tabular}{|c|c|c|c|c|c|}
\hline & $\begin{array}{l}\text { Ventricular } \\
\text { tumors }\end{array}$ & $\begin{array}{c}95 \% \\
\text { CI }\end{array}$ & $\begin{array}{l}\text { Atrial } \\
\text { tumors }\end{array}$ & $\begin{array}{c}95 \% \\
\text { Cl }\end{array}$ & $\begin{array}{c}P \\
\text { value }\end{array}$ \\
\hline CPB & 80 & 67,92 & 65 & 53,77 & .05 \\
\hline Crossclamp & 52 & 42,62 & 39 & 29,49 & .03 \\
\hline CPB temperature & 28 & 25,31 & 31 & 30,33 & .05 \\
\hline Local invasion & $7(14 \%)$ & & $1(2 \%)$ & & .02 \\
\hline Surgical approach & & & & & .0001 \\
\hline Ventriculotomy & $19(44 \%)$ & & 0 & & \\
\hline Single atriotomy & $4(9 \%)$ & & $47(90 \%)$ & & \\
\hline Biatrial approach & 0 & & $4(8 \%)$ & & \\
\hline Aortotomy & $8(19 \%)$ & & $1(2 \%)$ & & \\
\hline $\begin{array}{c}\text { Extracardiac } \\
\text { resection }\end{array}$ & $11(26 \%)$ & & 0 & & \\
\hline Other & $1(2 \%)$ & & & & \\
\hline Gross total resection & $42(82 \%)$ & & $37(70 \%)$ & & .13 \\
\hline En bloc & 0 & & $12(23 \%)$ & & .0003 \\
\hline ASD closure & $1(2 \%)$ & & $14(26 \%)$ & & .0004 \\
\hline VSD closure & $1(2 \%)$ & & 0 & & .31 \\
\hline \multicolumn{6}{|l|}{ Concomitant operations } \\
\hline AVR & 0 & & $1(2 \%)$ & & .32 \\
\hline MVR & 0 & & $1(2 \%)$ & & .32 \\
\hline PVR & $1(2 \%)$ & & 0 & & .31 \\
\hline CABG & $4(8 \%)$ & & $11(21 \%)$ & & .06 \\
\hline Septal myectomy & $3(6 \%)$ & & $1(2 \%)$ & & .29 \\
\hline $\begin{array}{c}\text { Intraoperative } \\
\text { mortality }\end{array}$ & $2(4 \%)$ & & 0 & & .15 \\
\hline \multicolumn{6}{|c|}{ Postoperative complications } \\
\hline Arrhythmias & $16(31 \%)$ & & $14(26 \%)$ & & .62 \\
\hline Renal failure & $1(2 \%)$ & & $1(2 \%)$ & & .99 \\
\hline Wound infections & 0 & & $1(2 \%)$ & & .32 \\
\hline Neurologic & $1(2 \%)$ & & $1(2 \%)$ & & .99 \\
\hline Bleeding & $4(8 \%)$ & & $1(2 \%)$ & & .16 \\
\hline Pulmonary effusion & $2(4 \%)$ & & 0 & & .15 \\
\hline Pneumonia & 0 & & $1(2 \%)$ & & .16 \\
\hline
\end{tabular}

$C l$, Confidence interval; $C P B$, cardiopulmonary bypass; $A S D$, atrial septal defect; $V S D$, ventricular septal defect; $A V R$, aortic valve replacement; $M V R$, mitral valve replacement; $P V R$, pulmonary valve replacement; $C A B G$, coronary artery bypass grafting. Boldface indicates statistical significance.

\section{Postoperative Course}

Postoperative complications are shown in Table 3. Postoperative management was not significantly different from that of patients undergoing other types of cardiac surgery. There was no significant difference between postoperative complications in either group. There was no significant association between the size, surgical approach, or tumor type and occurrence of postoperative complications.

\section{Follow-up}

Follow-up was obtained in 45 (88\%) of the early ventricular tumor survivors at a mean follow-up time of $6.16 \pm 5.7$ years and in $47(89 \%)$ patients with atrial tumors at a mean follow-up time of $8.22 \pm 7.7$ years. A KaplanMeier survival curve is shown in Figure 1; there was no 


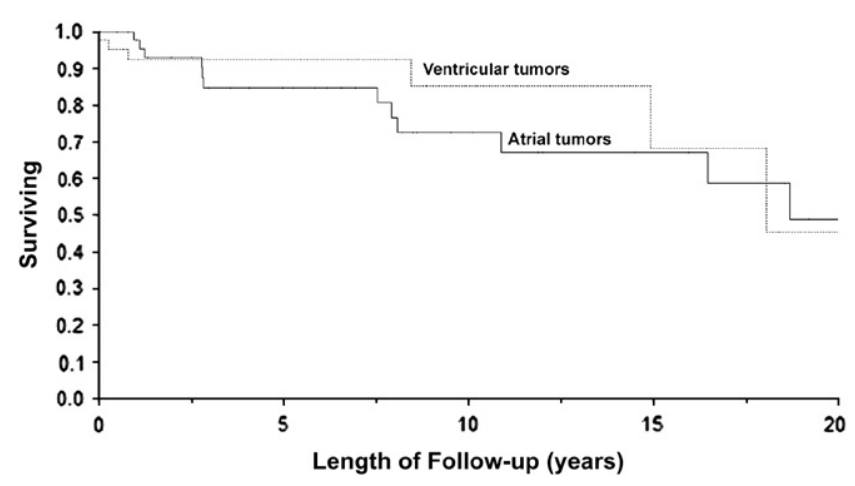

Figure 1. Kaplan-Meier survival curve: Atrial and ventricular tumors.

significant difference between the survival characteristics of patients who had atrial or ventricular tumor resection $(P=.55)$. Ten-year survival after atrial and ventricular tumor resection was $76 \%$ and $85 \%$, respectively. Within the ventricular tumor cohort, a Cox regression analysis indicated that there was a trend toward differences in the survival characteristics between the different histologic variants of tumors $\left(\chi^{2}=14.9 ; P=.06\right)$; however, this was due to the poor survival of one patient with an angiosarcoma. Tumor recurrence occurred in $3(6 \%)$ patients who had atrial tumors ( 2 myxoma recurrences and 1 malignant tumor recurrence) resected. There were no ventricular tumor recurrences $(P=.12)$. At the time of follow-up, $74 \%$ and $81 \%$ of patients who had atrial and ventricular tumors, respectively, were minimally symptomatic (New York Heart Association class I/II; $P=.13$ ).

\section{Discussion}

Previous literature has suggested that cardiac tumors produce symptoms by obstruction of intracardiac flow, arrhythmias resulting from myocardial invasion, embolization of tumor fragments, or constitutional symptoms via unclear mechanisms. ${ }^{7-13}$ This study further characterizes the epidemiology and spectrum of clinical symptoms of tumors arising from the ventricles and provides a direct comparison of the surgical effectiveness by comparing surgical outcomes to a randomly sampled cohort of patients who had atrial tumors resected. We chose to compare our surgical experience of ventricular tumor resection against atrial tumor resection, not only to provide epidemiologic, diagnostic, and pathophysiologic differences between these anatomic locations, but, more importantly, to assess whether surgical outcome was as effective in patients with ventricular tumors as in those with atrial tumors, since atrial tumor resection has long been understood to have excellent outcome if performed early. Timing for resection of ventricular tumors is controversial; however, on the basis of these data, early and late outcome after ventricular tumor resection is excellent and is not significantly different when compared with that of patients who undergo atrial tumor resection. It is important to note that all tissue diagnoses were made after tumor resection; this is a suitable strategy except in those patients in whom the diagnosis of a malignancy is questionable, in which case preoperative tissue diagnosis may be helpful in altering treatment strategy. These data indicate that early surgical resection of ventricular tumors confers an excellent short- and long-term prognosis.

\section{Ventricular Myxomas}

Although myxomas occur predominantly in the left atrium, ${ }^{6,14} 6$ patients (11\%) in this series had myxomas originating from the ventricles. In a review of 533 primary cardiac tumors, Blondeau ${ }^{15}$ found that ventricular myxomas are indeed rare, making up only 3\% of myxomas he and his colleagues identified. Our study further validates this assertion inasmuch as atrial myxomas were 7 times more likely to occur than ventricular myxomas. Ventricular and atrial myxomas have different hemodynamic consequences; as shown in this study, atrial myxomas cause congestive heart failure by atrial and valvular obstruction, ${ }^{16}$ whereas ventricular myxomas may cause a partial ventricular outflow tract obstruction or may have no effect on cardiovascular hemodynamics if the tumor is small and located in a region of the ventricle that does not affect intracardiac blood flow. In the majority of ventricular myxomas in this series, maximum tumor diameter was less than $2 \mathrm{~cm}$ and tumors were located away from the outflow tract; however, 2 patients did have significant outflow tract gradients owing to large myxomas protruding through the pulmonary valve. A feared sequela of atrial myxomas is the occurrence of embolic events occurring in as many as $40 \%$ of patients. ${ }^{7,17}$ In our series we appreciated $10(24 \%)$ patients with atrial myxomas who had a history of thromboembolic events. Interestingly, despite the fact that ventricular myxomas are subject to high intraventricular pressure, no patients in this cohort had a history of thromboembolic events.

\section{Ventricular Fibromas}

In our study, fibromas constituted the largest proportion of ventricular tumors, were largest in dimension, and occurred predominantly in the left ventricle (83\%), a skewed distribution that is most likely due to the relative amount of myocardial tissue. ${ }^{18}$ Fibromas have traditionally been characterized as tumors occurring in the pediatric population. ${ }^{19}$ However, we identified $8(44 \%)$ patients who were above the age of 18. Although most patients were asymptomatic, those who were symptomatic had palpitations and ventricular tachycardia, a finding that is best explained by the close proximity to the conduction system and the massive tumor size. The appearance of cardiac fibromas can be quite impressive given their size, leading some to lobby for cardiac transplantation in patients with large fibromas. ${ }^{20-22}$ Indeed, 3 patients with ventricular fibromas were referred to our clinic for cardiac 
transplantation, but subsequently underwent complete excision without complication and were alive at follow-up. Fibromas are unencapsulated tumors and can often be simply peeled away from the underlying myocardium after hypothermic cardiopulmonary bypass and cardioplegic myocardial protection. In fact, a significant proportion of patients in this series did not require an intracardiac approach.

The natural history of the fibroma is unpredictable; there have been numerous reports in the literature of asymptomatic patients dying unexpectedly, ${ }^{23-25}$ presumably of arrhythmias. A major operative concern is intimate contact these tumors may have with the coronary arteries ${ }^{20}$; one death in this study was attributed to surgical trauma of the left anterior descending coronary artery. In cases in which the tumor may be closely approximated to a coronary artery, we recommend a subtotal excision, as performed in 1 patient in this series who had repeat echocardiograms with no evidence of tumor growth. Subtotal excision should also be exercised when there is risk of significantly affecting cardiac function owing to complete fibroma resection. ${ }^{26,27}$

\section{Ventricular Papillary Fibroelastomas}

Papillary fibroelastomas were the second most common tumor identified in this series. These tumors were also most likely to occur in the left ventricle $(81 \%)$ and specifically the left ventricular outflow tract. In a recent study of all patients with papillary fibroelastomas from our institution, 54 patients were described, with only $6(11 \%)$ patients having tumors arising from the left ventricle. Papillary fibroelastomas were most often found on the valvular endocardium and diagnosed by their stereotypic echocardiographic appearance-a pedunculated, mobile mass. ${ }^{28}$ The susceptibility for embolic potential has been well documented in the literature. ${ }^{29}$ In our series, 3 (23\%) patients with ventricular papillary fibroelastomas had a history of embolic events or transient ischemic attacks. Despite the embolic potential of these tumors, 5 (45\%) patients were asymptomatic and found to have papillary fibroelastomas incidentally, thus speaking to the unpredictable nature of this tumor.

The etiology of ventricular papillary fibroelastomas may be closely linked to primary cardiac diseases and previous cardiac surgery. ${ }^{28,30,31}$ Of the 11 patients in this series, 7 (64\%) had concurrent cardiac disease including 4 patients with hypertrophic obstructive cardiomyopathy ( 2 with previous septal myectomy), 1 who had a previous cardiac surgery for ventricular septal defect closure, and 2 with aortic stenosis. These findings suggest that papillary fibroelastomas may arise in response to either iatrogenic surgical trauma or pressure-induced trauma. ${ }^{30}$ Although clinical presentation can be quite variable, studies have compared the outcome of patients who undergo surgical resection versus those treated conservatively. ${ }^{28}$ Twenty-two percent of patients in a recent series treated conservatively (without surgery) were found to have neurologic events and $4 \%$ with peripheral embolic events in the follow-up period. No patients in the surgical group of that study had any evidence of central or peripheral embolic events in the follow-up period. Despite their small size, the likelihood of both central and peripheral embolic events is high.

\section{Ventricular Hamartomas}

Myocardial hamartomas (Purkinje cell) are tumors that are not clearly understood but have been implicated in electrical disturbances that may result in sudden death. ${ }^{16}$ Our study included 4 (8\%) patients with hamartomas (3 pediatric); 3 had palpitations/ventricular arrhythmias and 1 had vague constitutional symptoms and new-onset dyspnea. Although hamartomas are much smaller than fibromas (mean tumor burden, $71 \mathrm{vs} 120 \mathrm{~cm}^{3}$ ), presenting symptoms are similar. Also similar is the fact that there have been many documented cases of patients dying of an arrhythmia. ${ }^{32}$ Given the risk of sudden death and excellent surgical outcome, it is our opinion that patients with hamartomas should be aggressively treated with surgical resection. All tumors in this series were approached by ventriculotomy, and total resection was performed in all cases.

In the preoperative evaluation, it is important to differentiate between hamartomas and rhabdomyomas (the most common cardiac tumor in pediatric patients). Although this may be difficult at the time of clinical presentation given similarities in epidemiology, anatomic size, and location, rhabdomyomas can often be accurately diagnosed based on therir multiplicity and strong association with tuberous sclerosis. ${ }^{33,34}$ However, they can often be accurately diagnosed owing to their multiplicity and strong association with tuberous sclerosis. ${ }^{35}$ In contrast to our experience with hamartomas, it has been shown that patients with cardiac rhabdomyomas should not be considered candidates for surgical resection unless they have severe symptoms refractory to medical treatment inasmuch as these tumors are likely to regress with time. ${ }^{36-38}$

\section{Other Benign Ventricular Tumors}

Our experience with ventricular tumors also included multiple patients with hemangiomas and lipomas. Hemangiomas are rare and represent less than $3 \%$ of all tumors of the heart. ${ }^{4}$ These tumors can involve the epicardium, myocardium, or endocardium; 2 tumors we identified were intracardiac and 1 was epicardial. However, all underwent resection via cardiopulmonary bypass, ventriculotomy, complete tumor resection, and primary suture closure of the ventricle. Lipomas also present with vague symptoms and have been reported to occur in almost any region of the heart. Interestingly, we resected a $463-\mathrm{cm}^{3}$ epicardial cardiac lipoma from a patient whose only symptom was occasional palpitations.

\section{Malignant Ventricular Tumors}

The most common presenting symptoms of malignant cardiac tumors are congestive heart failure, chest pain, and 
constitutional symptoms. ${ }^{39}$ Angiosarcomas are the most common malignant cardiac tumor, have a predilection for the right side of the heart, ${ }^{40,41}$ and occur principally in the right atrium. Our only malignant ventricular tumor was in a patient with an angiosarcoma who had vague constitutional symptoms. After median sternotomy and frozen section tumor biopsy were performed (revealing grade 4 angiosarcoma), resection was not attempted because the mass was highly invasive, encompassing the right ventricular free wall, septum, and tricuspid valve. This patient was subsequently treated with adjuvant chemotherapy. However, metastatic disease developed and death occurred within 9 months of surgery, emphasizing the highly aggressive nature of this tumor. We are aware of 3 other patients who came to our institution with highly invasive angiosarcomas of the ventricle but were not offered surgical treatment. Prognosis for malignant tumors of the heart has historically been very poor, with most patients dying within 1 year. ${ }^{40,42-44} \mathrm{We}$ and others recommend that attempts at resection be performed only when there is no evidence of metastatic disease or when there is severe hemodynamic compromise owing to tumor invasion. Postoperatively, these patients should subsequently undergo aggressive adjuvant chemotherapy inasmuch as there is now increasing evidence that some chemotherapeutic regimens may initiate a favorable outcome even when there is no evidence of metastasis. ${ }^{45,46}$

\section{Conclusions}

Primary ventricular tumors vary in clinical presentation, anatomic location, and operative strategy. Despite this diversity, short- and long-term outcome after resection is excellent. Although atrial myxomas are the most common cardiac tumor, we identified 6 histologic variants of benign ventricular tumors occurring in multiple patients and 1 malignant tumor with a similar complication rate and survival profile of our control group. On the basis of these results, we believe that early surgical resection should be considered for ventricular tumors.

\section{Limitations}

This is a retrospective cohort study with a study group consisting of patients who had surgery for ventricular tumor resection and a reference group of patients who had surgery for atrial tumor resection. Although the number of patients in our study group was small, given the rarity of ventricular tumors, this represents the largest study of patients with ventricular tumor resection while providing a context for interpretation of surgical outcome. Our main limitation is the generalizability of these results to patients with all types of ventricular tumors. Because ventricular tumors are diverse in histologic type, location, and size, it is important that all patients be evaluated closely with regard to timing and surgical strategy of resection.

\section{References}

1. Silverman N. Primary cardiac tumors. Ann Surg. 1980;191:127-38.

2. Chitwood WR Jr. Cardiac neoplasms: current diagnosis, pathology, and therapy. J Card Surg. 1988;3:119-54.

3. Benjamin H. Primary fibromyxoma of the heart. Arch Pathol. 1939;27: 950-62.

4. McAllister HA Jr, Hall RJ, Cooley DA. Tumors of the heart and pericardium. Curr Probl Cardiol. 1999;24:57-116.

5. Heath D. Pathology of cardiac tumors. Am J Cardiol. 1968;21:315-27.

6. Reynen K. Cardiac myxomas. N Engl J Med. 1995;333:1610-7.

7. Larrieu AJ, Jamieson WR, Tyers GF, Burr LH, Munro AI, Miyagishima RT, et al. Primary cardiac tumors: experience with 25 cases. J Thorac Cardiovasc Surg. 1982;83:339-48.

8. Vander Salm TJ. Unusual primary tumors of the heart. Semin Thorac Cardiovasc Surg. 2000;12:89-100.

9. Wold LE, Lie JT. Cardiac myxomas: a clinicopathologic profile. Am J Pathol. 1980;101:219-40.

10. St John Sutton MG, Mercier LA, Giuliani ER, Lie JT. Atrial myxomas: a review of clinical experience in 40 patients. Mayo Clin Proc. 1980;55: 371-6.

11. Goodwin JF. Diagnosis of left atrial myxoma. Lancet. 1963;1:464-8.

12. Goodwin JF. The spectrum of cardiac tumors. Am J Cardiol. 1968;21: 307-14.

13. Greenwood WF. Profile of atrial myxoma. Am J Cardiol. 1968;21: 367-75.

14. Actis Dato GM, De Benedictis M, Actis Dato A Jr, Ricci A, Sommariva L, De Paulis R. Long-term follow-up of cardiac myxomas (7-31 years). J Cardiovasc Surg (Torino). 1993;34:141-3.

15. Blondeau P. Primary cardiac tumors-French studies of 533 cases. Thorac Cardiovasc Surg. 1990;38(Suppl 2):192-5.

16. Murphy MC, Sweeney MS, Putnam JB Jr, Walker WE, Frazier OH, Ott DA, et al. Surgical treatment of cardiac tumors: a 25-year experience. Ann Thorac Surg. 1990;49:612-7; discussion 617-8.

17. Miralles A, Bracamonte L, Soncul H, Diaz del Castillo R, Akhtar R, Bors V, et al. Cardiac tumors: clinical experience and surgical results in 74 patients. Ann Thorac Surg. 1991;52:886-95.

18. Cho JM, Danielson GK, Puga FJ, Dearani JA, McGregor CG, Tazelaar HD, et al. Surgical resection of ventricular cardiac fibromas: early and late results. Ann Thorac Surg. 2003;76:1929-34.

19. Molina JE, Edwards JE, Ward HB. Primary cardiac tumors: experience at the University of Minnesota. Thorac Cardiovasc Surg. 1990;38(Suppl 2):183-91.

20. Stiller B, Hetzer R, Meyer R, Dittrich S, Pees C, Alexi-Meskishvili V, et al. Primary cardiac tumours: when is surgery necessary? Eur J Cardiothorac Surg. 2001;20:1002-6.

21. Valente M, Cocco P, Thiene G, Casula R, Poletti A, Milanesi O, et al. Cardiac fibroma and heart transplantation. J Thorac Cardiovasc Surg. 1993;106:1208-12.

22. Michler RE, Goldstein DJ. Treatment of cardiac tumors by orthotopic cardiac transplantation. Semin Oncol. 1997;24:534-9.

23. Parmley LF, Salley RK, Williams JP, Head GB 3rd. The clinical spectrum of cardiac fibroma with diagnostic and surgical considerations: noninvasive imaging enhances management. Ann Thorac Surg. 1988; 45:455-65.

24. Burke AP, Rosado-de-Christenson M, Templeton PA, Virmani R. Cardiac fibroma: clinicopathologic correlates and surgical treatment. J Thorac Cardiovasc Surg. 1994;108:862-70.

25. Cina SJ, Smialek JE, Burke AP, Virmani R, Hutchins GM. Primary cardiac tumors causing sudden death: a review of the literature. Am J Forensic Med Pathol. 1996;17:271-81.

26. Bertolini P, Meisner H, Paek SU, Sebening F. Special considerations on primary cardiac tumors in infancy and childhood. Thorac Cardiovasc Surg. 1990;38(Suppl 2):164-7.

27. Cotton JL, Kavey RE, Palmier CE, Tunnessen WW Jr. Cardiac tumors and the nevoid basal cell carcinoma syndrome. Pediatrics. 1991;87: 725-8.

28. Klarich KW, Enriquez-Sarano M, Gura GM, Edwards WD, Tajik AJ, Seward JB. Papillary fibroelastoma: echocardiographic characteristics for diagnosis and pathologic correlation. J Am Coll Cardiol. 1997;30: 784-90. 
29. Brown RD Jr, Khandheria BK, Edwards WD. Cardiac papillary fibroelastoma: a treatable cause of transient ischemic attack and ischemic stroke detected by transesophageal echocardiography. Mayo Clin Proc. 1995;70:863-8.

30. Kurup AN, Tazelaar HD, Edwards WD, Burke AP, Virmani R, Klarich KW, et al. Iatrogenic cardiac papillary fibroelastoma: a study of 12 cases (1990 to 2000). Hum Pathol. 2002;33:1165-9.

31. Cesena FH, Pereira AN, Dallan LA, Aiello VD, Mansur AJ. Papillary fibroelastoma of the mitral valve 12 years after mitral valve commissurotomy. South Med J. 1999;92:1023-8.

32. Kearney DL, Titus JL, Hawkins EP, Ott DA, Garson A Jr. Pathologic features of myocardial hamartomas causing childhood tachyarrhythmias. Circulation. 1987;75:705-10.

33. Fenoglio JJ Jr, McAllister HA Jr, Ferrans VJ. Cardiac rhabdomyoma: a clinicopathologic and electron microscopic study. Am J Cardiol. 1976;38:241-51.

34. Geva T, Santini F, Pear W, Driscoll SG, Van Praagh R. Cardiac rhabdomyoma. Rare cause of fetal death. Chest. 1991;99:139-42.

35. Bosi G, Lintermans JP, Pellegrino PA, Svaluto-Moreolo G, Vliers A. The natural history of cardiac rhabdomyoma with and without tuberous sclerosis. Acta Paediatr. 1996;85:928-31.

36. Farooki ZQ, Ross RD, Paridon SM, Humes RA, Karpawich PP, Pinsky WW. Spontaneous regression of cardiac rhabdomyoma. Am J Cardiol. 1991;67:897-9.

37. Matsuoka Y, Nakati T, Kawaguchi K, Hayakawa K. Disappearance of a cardiac rhabdomyoma complicating congenital mitral regurgitation as observed by serial two-dimensional echocardiography. Pediatr Cardiol. 1990;11:98-101.
38. Nir A, Tajik AJ, Freeman WK, Seward JB, Offord KP, Edwards WD, et al. Tuberous sclerosis and cardiac rhabdomyoma. Am J Cardiol. 1995;76:419-21.

39. Bakaeen FG, Reardon MJ, Coselli JS, Miller CC, Howell JF, Lawrie GM, et al. Surgical outcome in 85 patients with primary cardiac tumors. Am J Surg. 2003;186:641-7; discussion 647.

40. Burke AP, Cowan D, Virmani R. Primary sarcomas of the heart. Cancer. 1992;69:387-95.

41. Herrmann MA, Shankerman RA, Edwards WD, Shub C, Schaff HV. Primary cardiac angiosarcoma: a clinicopathologic study of six cases. J Thorac Cardiovasc Surg. 1992;103:655-64.

42. Poole GV Jr, Breyer RH, Holliday RH, Hudspeth AS, Johnston FR, Cordell AR, et al. Tumors of the heart: surgical considerations. J Cardiovasc Surg (Torino). 1984;25:5-11.

43. Reece IJ, Cooley DA, Frazier OH, Hallman GL, Powers PL, Montero CG. Cardiac tumors: clinical spectrum and prognosis of lesions other than classical benign myxoma in 20 patients. J Thorac Cardiovasc Surg. 1984;88:439-46.

44. Wiske PS, Gillam LD, Blyden G, Weyman AE. Intracardiac tumor regression documented by two-dimensional echocardiography. Am J Cardiol. 1986;58:186-7.

45. Leu KM, Ostruszka LJ, Shewach D, Zalupski M, Sondak V, Biermann JS, et al. Laboratory and clinical evidence of synergistic cytotoxicity of sequential treatment with gemcitabine followed by docetaxel in the treatment of sarcoma. J Clin Oncol. 2004;22:1706-12.

46. Fata F, O'Reilly E, Ilson D, Pfister D, Leffel D, Kelsen DP, et al. Paclitaxel in the treatment of patients with angiosarcoma of the scalp or face. Cancer. 1999;86:2034-7. 